\title{
Application of Gauss-Kronrod Quadrature Method for Solving Non-Linear Integro-differential Equations of the second kind
}

\author{
Nedjem Eddine Ramdani ${ }^{1}$ \\ ${ }^{1}$ Saad Dahlab University of Blida
}

October 8, 2020

\begin{abstract}
In this paper, we deal with the non-linear integro-differential equation in which we proposed a quadrature method in order to find an approximate solution. We provide an error analysis and we conclude by giving the algorithm.
\end{abstract}

\section{Hosted file}

Application of Gauss-Kronrod Quadrature Method for Solving Non-Linear Integro-differential Equations.pd available at https://authorea.com/users/365392/articles/485498-application-of-gauss-kronrodquadrature-method-for-solving-non-linear-integro-differential-equations-of-the-secondkind

\section{Hosted file}

Application of Gauss-Kronrod Quadrature Method for Solving Non-Linear Integro-differential Equations.te available at https://authorea.com/users/365392/articles/485498-application-of-gauss-kronrodquadrature-method-for-solving-non-linear-integro-differential-equations-of-the-secondkind 